\title{
Impact of COVID-19 on Surgical Residency Training: Indian Perspective - A Review
}

\author{
Chetan V Kantharia ${ }^{1}$, Sharvari Pujari², Kishor Jain ${ }^{3}$, Ramkrishna Prabhu ${ }^{4}$ \\ ${ }^{1,2,3,4}$ Department of Surgical Gastroenterology, Seth GS Medical College and KEM Hospital, Parel, Mumbai-12
}

Corresponding Author: Chetan V Kantharia

\begin{abstract}
Introduction: The COVID-19 pandemic has severely affected the health delivery system. The residency training program has had a major setback, with a maximum impact on surgical residency training. This study attempts to explore the extent of impact of COVID-19 on Surgical Residency training and the corrective measures to be taken from the trainee's perspective.
\end{abstract}

Methods: A Questionnaire was made and response was sought from the surgical trainees. The aspects of surgical training assessed were; the impact on hands on surgical training, bedside clinical teaching, efficacy of the alternative virtual academic program and the OSCE based assessment. Suggestions were also sought with regards to the remedial measures needed to be taken. The responses were compiled and conclusion was drawn. Statistical analysis was made using SPSS software programme.

Results: A total of 68 residents participated in the survey. Of these, 17 (25.37\%) were first year residents ( 6 from Govt and 11 from private institute), 26 (38.23\%) second year (9 from Govt and 17 from private institute), and 25 (36.76\%) third year residents (10 from Govt and 15 from private institute). The responses were analysed. All respondents reported decrease in clinical workload ranging from 50 to $90 \%$. The reported loss of surgical experience too ranged from $50-90 \%$ depending on the seniority of the residents. Operative autonomy too was experienced by only $13.23 \%$ of respondents. Reported decrease in the Bed side clinical training ranged from 50 to $95 \%$ All the respondents reported increase and benefits of online academic sessions with overall score $>5$ on a scale of 1-10. All the respondents (100\%) approved of the OSCE pattern of exams held by the NBE board.
Conclusions: The COVID-19 pandemic has adversely impacted surgical training. There is a need to assess the future training program advancement, with the need to include remedial measures, and adopting an individualized approach. The OSCE pattern of examination conducted has been accepted by all and recommended to be integrated as a part of the practical exams in future too. The virtual learning and telemedicine embraced in the time of pandemic, has had a great impact in enhancing surgical education

Key words: COVID 19-infection, Impact on Residency training Program

\section{INTRODUCTION}

The COVID-19 pandemic has had a global impact on the health sector and the health delivery system ${ }^{(1)}$. The COVID -19 pandemic, beginning from March 2020 when the first wave began to the ongoing second wave has now spanned for more than a year. In order to control the infection, and owing to the resource constraint of medical professionals, reconfiguration of health services was done nationally. The resources of specialist medical traineesdoing their residency were channelised in managing the COVID-19 patients. The focus of health delivery system has primarily been prioritized to manage COVID affected patients. This has had adversely affected the existing structured residency program encompassing all the specialities in general, but more so on the surgical residency training in particular ${ }^{(2,3)}$. Being a stake holder in imparting academic training, it is important to assess the extent of impact from the trainee's point of view, 
and to try to understand the suggestions of residents for remedial measures. It is also important to ensure implementation of the suggested remedial measures, and ensure that the residents complete the training, meeting the predefined objectives. The present study is a survey carried out to understand the perspective from surgical residents' point of view on the impact of COVID-19 pandemic on clinical workload, academics, operative volume and autonomy and overall impact. Besides it also attempts to understand what the residents feel is the best remedial measure to be taken to overcome the deficiency occurred, and restore back the confidence required to progress to the next stage of training.

\section{METHODS}

This is a prospective observational study. A questionnaire was designed as per the established guidelines on survey-based research ${ }^{(4)}$. The questionnaire comprised of both closed- and open-ended questions, assessing the impact on clinical workload, academics, operative volume and autonomy, overall impact and the remedial recommendations. (Table: I) The questionnaire was sent to trainees of a particular surgical super specialty branch pursuing their MCh /DNB degree, across the nation through email, WhatsApp and Telegram group on first week of April. Responses were collected over two months period until May last week (including the peak of second wave of pandemic). Participation in the study was completely voluntary and no incentives were offered to participate in the study. Responses were sought from all grades of trainees in that particular speciality. Participation from post Mch/DNB residents, Associate and Junior Consultants, Faculties and Senior Consultants was excluded. Data was compiled from fully completed questionnaire. Statistical analysis was done using SPSS software program.

\section{TABLE: I QUESTIONAAIRE}

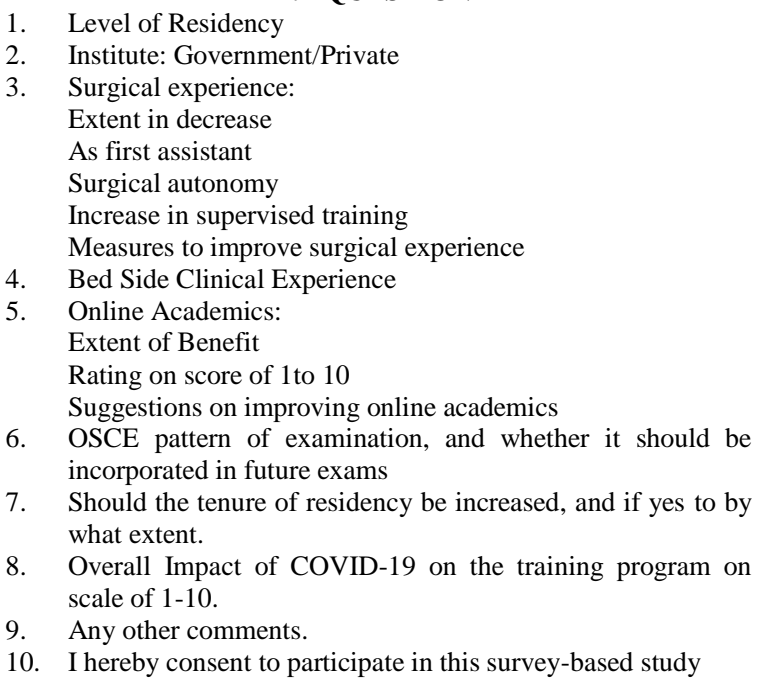

\section{RESULTS}

A total of 68 residents participated in the survey. This constituted to $22.66 \%$ of the total number of residents in the particular Super-specialty branch. Of these, $17(25.37 \%)$ were first year residents (6 from Govt and 11 from private institute), 26 (38.23\%) second year ( 9 from Govt and 17 from private institute), and $25(36.76 \%)$ third year residents (10 from Govt and 15 from private institute). All the respondents reported decrease in clinical workload with the respondents reporting a decrease from 50 to $90 \%$, with a mean of $70 \%$. All the respondents also reported a decrease in surgical experience. With regards to the extent in decrease in surgical experience, the first-year residents reported $90 \%$ decrease, the second year $70 \%$ and the final third year residents 50\%. Only 30 residents got to assist as first assistant (44.11\%). Operative autonomy was experienced by only 9 third year residents, constituting $13.23 \%$. Of the 9 who experienced surgical autonomy, $6(66.66 \%)$ reported increase in supervised training. All the respondents reported decrease in bed side clinical training, with the first-year residents reporting decrease of $95 \%$, second year $70 \%$ and third year 50\% decrease. All the respondents reported increase in online academic sessions and its benefits. On a scale of 1 to 10 with regards to benefit of online academics, the mean score was 6 as 
rated by first-year residents, 8 by second year and 10 by third year residents. All the respondents $(100 \%)$ approved of the OSCE pattern of exams held by the NBE board, with only $43(63.23 \%)$ experiencing it. However all (100\%) wanted OSCE pattern to be part of their exams in future. Only two respondents (both first year resident from private institutes) were for increase in the tenure of residency and that too not for more than six months. Rest 66 (97.05\%) were not for increase in tenure of residency. All respondents reported a negative impact on their training, with the adverse effect being rated as 10 on a scale of 1-10. As far as suggestions of the respondents were concerned, all the respondents (100\%) wanted increased hands-on surgical experience, $47(69.11 \%)$ wanted to attend surgical workshops. With regards to suggestions on online academics, 29 $(42.64 \%)$ wanted sessions of lesser duration, $57(85 \%)$ wanted sessions on practical topics and $100 \%$ wanted case based online academics. $7 \quad(10.29 \%)$ respondents specifically mentioned about mental stress when asked to comment on any other matter. (Summary of Results: Table II)

TABLE II: Summary of Result

\begin{tabular}{|c|c|c|c|}
\hline & $\begin{array}{l}1^{\text {st }} \text { YEAR } \\
\text { RESIDENT }\end{array}$ & $\begin{array}{l}2^{\mathrm{ND}} \text { YEAR } \\
\text { RESIDENT }\end{array}$ & $\begin{array}{l}3^{\mathrm{RD}} \text { YEAR } \\
\text { RESIDENT }\end{array}$ \\
\hline NUMBER & 17 & 26 & 25 \\
\hline INSTITUTE & & & \\
\hline GOVT & 6 & 9 & 10 \\
\hline PRIVATE & 11 & 17 & 15 \\
\hline EXTENT OF DECREASE IN SURGICAL EXPERIENCE & $90 \%$ & $60 \%$ & $25 \%$ \\
\hline EXTENT OF DECREASE IN BED SIDE CLINICAL TEACHING & $95 \%$ & $70 \%$ & $50 \%$ \\
\hline RATING OF BENEFIT OF ONLINE ACADEMICS ON A SCORE OF 1-10 & 6 & 8 & 10 \\
\hline $\begin{array}{l}\text { INCORPORATION OF OSCE PATTERN OF EXAMINATION FOR } \\
\text { FUTURE }\end{array}$ & $\begin{array}{l}\text { YES, } \quad \text { BY } \\
\text { ALL }\end{array}$ & YES & YES \\
\hline $\begin{array}{l}\text { SHOULD TENURE OF RESIDENCY BE INCREASED AND BY WHAT } \\
\text { DURATION }\end{array}$ & $\begin{array}{l}\text { NO: } 15 \\
\text { YES: } 2\end{array}$ & NO & NO \\
\hline $\begin{array}{l}\text { OVERALL IMPACT ON SURGICAL TRAINING } \\
\text { SCOREOF } 1-10\end{array}$ & $\begin{array}{l}\text { NEGATIVE } \\
10\end{array}$ & $\begin{array}{l}\text { NEGATIVE } \\
10\end{array}$ & $\begin{array}{l}\text { NEGATIVE } \\
9\end{array}$ \\
\hline
\end{tabular}

\section{DISCUSSION}

The COVID-19 pandemic has affected the health delivery system, especially the surgical speciality globally ${ }^{(5)}$. A reconfiguration of health services was also done, with trainees across all the specialities posted to manage the COVID19 patients. This happened not only in our country but globally ${ }^{(6)}$. The deployment of the services of the surgical residents across all the surgical subspecialties in the management of COVID patients, led to rescheduling of their normal rotational duties. This has led to disruption of the normal surgical training, spanning now for over a year.

\section{Clinical workload:}

Since last week of March 2020, when the nation went under first lockdown, elective indoor admissions were restricted. This led to significant decrease in the clinical workload. As per the need of the hour, in order to make beds available for the COVID patients, only patients of malignancy and those requiring emergency intervention were being admitted. Another reason for the decrease in the clinical workload could be reluctance due to fear amongst the patients to get admitted for elective procedures, during the pandemic. In the present study, the respondents reported a decrease in clinical workload ranging from 50 to $90 \%$, with a mean of $70 \%$. Ellison et al $^{(7)}$, in their survey reported similar finding including both indoor and outdoor patient load.

\section{Operative workload and Operative autonomy:}

Restricted indoor admission, and surgical interventions only for emergency and oncological indications, led to decrease in number of surgeries being performed and correspondingly reduction in surgical training opportunities. As per a report, it has 
been predicted that over 28 million elective cases were cancelled during the first wave of the pandemic in early $2020^{(8)}$. Reduction in surgery has been observed across all the specialities of surgery, including general surgery ${ }^{(9)}$, orthopaedic surgery ${ }^{(10)}$, and neurosurgery (11) amongst other subspecialties. Besides, with the existing hierarchical and efficiency-based model as reported by study of Chloe $\mathrm{S}^{(12)}$, and to reduce the operative time and risk of intraoperative transmission of infection, most of the surgeries were performed by consultants/faculty cadre ${ }^{(13)}$, thus reducing the trainees' operative opportunities, with resident trainee surgeons at the best being first or second assistant. However, Ellison et al ${ }^{(7)}$ in their survey have reported only 14 $18 \%$ of surgical trainees reporting loss of operative autonomy, and majority of respondents reporting no negative impact on operative autonomy. In this context, it is important to know that many a times the surgical trainees are not in a best position to judge their own surgical skill and competency ${ }^{(14)}$. This holds true particularly for third year exam going residents who have a false sense of feeling that they have seen all and can do all. Literature survey suggests, different experiences for trainees at different stages in training $20,21,2215,16,17$. In the present study the reported decrease in work-load was $90 \%$ by first-year residents, $70 \%$ by the second year and $50 \%$ by final third year residents. Besides, only 30 residents got to assist as first assistant $(44.11 \%)$. This could be due to the fact that, the junior residents were assigned to do COVID rotational duties more than their senior counterparts. Operative autonomy too in this study was reported by only 9 $(13.23 \%)$, all being third year residents, and $6(66.66 \%)$ of them reporting increase in supervised training. The ultimate objective of a surgical training is the preparedness of the trainee to perform surgical procedure independently with optimal safety. Though the number of surgeries performed independently, or under supervision, does not reflect this objective, it does serve as a surrogate parameter to judge the trainees experience and surgical exposure. Although there are various online platforms on which operative videos are available, they can never substitute the actual hands-on experience obtained by operating or assisting. Hands-on surgical training remains the foundation of a surgical training, on which a trainee, builds his surgical career. In this context, the operative videos only serve to bridge the gap and fine tune the operative skills. This highlights an important fact that these residents, especially the final year residents' need increased surgical exposure post pandemic period, to fulfil their objective of surgical training.

\section{Bedside Clinical Teaching:}

Bedside clinical teaching is an essential component of clinical training. Bedside teaching not only facilitates trainees to know important clinical signs which helps to clinch diagnosis, discuss the case in detail with regards to its management, but also to master the art of patient communication. However, during the pandemic, due to restricted indoor admissions, increased rotation in COVID ward, the need to maintain safe distance and the donning of PPE Kit while examining the patients led to significant decrease in the bed side clinical teaching. Though there is no literature evidence addressing this issue in particular, in the present study all the respondents reported decrease in bed side clinical training, with the first-year residents reporting $95 \%$, second year $70 \%$ and third year $50 \%$ decrease. This implies that the while the third -year residents were more actively involved in the clinical management of the patients, the services of the first- and second-year residents were more utilised in the management of COVID patients.

\section{Academic teaching program:}

With the need to maintain safe distance, and owing to restricted admissions, the bed side clinical teaching 
and the formal clinical meetings, clinical seminars, case-based discussions and Journal club meetings were badly affected. Because of the compulsory rotational COVID duties, though the residents gained vital experience in intensive care management of critical patients and an enhancement in their knowledge of principles of medicine, this was at a heavy price of loss of surgical skill and clinical experience and teaching. However, majority of the teaching institutes adopted virtual platforms for clinical teaching ${ }^{(18)}$. In the present study, all the respondents reported increase in online academic sessions and that it was of benefit to them. When asked to rate on a scale of 1 to 10 with regards to benefit of online academics, the mean rating of score was 6 by first-year residents, 8 by second year and 10 by third year residents. The resident community in whom this survey was carried out, belonged to a super specialty, whose national association otherwise too, conducts weekly online telemedicine-case presentation and discussion and also monthly resident seminar on an important topic. These sessions further increased during the pandemic. The important feature of these online sessions was that the residents were encouraged to participate actively and all their queries were solved by the moderating faculties. Besides this, there were various other organisations and societies which conducted relevant online academic programs in this particular speciality. This explains the overall satisfaction among the respondents with the online academic programs conducted. Online academic programs have witnessed not only increased participation going by the number of residents logged in for each session, but also increased exposure to eminent faculties both national and international. However, the concern is, as to whether increase participation ensures effective delivery of the content, a point which is debatable. This is because, there can be instances where a trainee may have logged in, but not actively participating. Hence online academic teaching programs can best serve as adjunct to bridge the vital clinical training missed by residents ${ }^{(19)}$. Besides, no virtual programs including operative videos giving practical tips, or OSCE based teaching can replace bed-side clinical teaching and hands-on operative training ${ }^{(20)}$.

\section{Overall Impact:}

All the respondents have reported an overall negative impact of the COVID-19 infection on their surgical training. All rated the adverse effect a score of 10 on a scale of 1-10. This is in accordance with the systematic review by Hope et al ${ }^{(21)}$. Besides as reported by Munro et al in their study, in the present study too, most of the respondents felt that their objective of surgical training was unmet (22). The positives gained from COVID-19 pandemic were; increased online academic teaching, exposure to eminent national and international faculties and more time gained by trainees to pursue their research activities. All the respondents also reported an enhanced skill in the intensive care management of patients. But this opportunity to enhance their other competencies was at the cost of technical and operative skill. ${ }^{7}$

\section{Remedial measures as suggested by respondent Trainees:}

The finding in this study is in unanimity with various other studies, with regards to loss of operative experience, exposure and autonomy. All the respondents $(100 \%)$ wanted increased hands-on surgical experience. $47(69.11 \%)$ wanted to attend surgical workshops to enhance their surgical skills. Although all respondents admitted to have lost out on operative experience, $97 \%$ respondents in this study did not want their tenure of residency to be increased. This finding is in keeping with report by COVID-STAR Collaborative Study Group ${ }^{23}$. This can be explained by the fact that this survey involves Super-Specialty trainees, who have a fair amount of surgical exposure and maturity and are keen to complete their 
exit exams and advance further in their surgical career. Besides most of them would have to complete their bond post exit exams, when they would look to make up for the loss in operative experience. With regards to suggestions on online academics, 29 $(42.64 \%)$ wanted sessions of lesser duration so as to enable them to maintain attention span. 57(85\%) wanted sessions on practical topics and $100 \%$ wanted increased case based online academics.

\section{Our Recommendations:}

The unusual problem of surgical trainees calls for a personalised approach. The need of the hour is that each trainee should be addressed individually, identifying individual trainee's shortcoming, areas demanding attention and make best efforts to bridge the gap created. However, this would call for increased motivation on part of the faculty. Also, it is important to ensure that the trainees get an adequate operative experience at-least as first assistant if not independent operative experience, depending on their seniority. The tenure of the trainee's residency should not be extended, as suggested by $97 \%$ of respondents in the study. However, it is a must that they need to work post exit exams at least for a year, as Senior residents completing their bond or as associate or Junior consultant, in order to gain confidence to work independently. Besides this will ensure that the trainees obtain adequate skills ensuring safe and effective care to patients. This suggestion however is open to debate. In UK, the Joint Committee on Surgical Training in collaboration with the Association of Surgeons in Training, British Orthopaedics Trainees' Association, and Confederation of Postgraduate Schools of Surgery published a report ${ }^{(24)}$ suggesting several remedial measures to guide the recovery. Amongst the several recommendations made, the important recommendations were expanding the use of online platforms, and developing simulation opportunities to make up for the deficiency in technical skills. However, in our set up, though the former is feasible the later would be possible only in select few centres.

\section{Limitations of the study:}

This study is based on a survey of a particular Surgical Super-specialty branch, though it echoes and reflects the sentiments of all surgical trainees across all the specialty. The number of participants in the study are small, with only $22.6 \%$ of the total number of trainees in the specialty participating. The reason for this could be varied, it being lack of motivation to participate in the survey, or feeling of being low owing to COVID duties, or a remorse that not much can change their fate. Although $7 \quad(10.29 \%)$ respondents specifically mentioned about mental stress in the survey, this study does not take into account affection of mental health and wellbeing of the trainees. This is the most important limitation of this study. However, this is a topic of discussion by itself and has been addressed by various studies ${ }^{25,26}$

\section{CONCLUSION}

COVID-19 pandemic has had a significant impact on the surgical training residency Program. It has led to overall decrease in clinical and hands on surgical experience. This has resulted in the trainee's inability to progress and enhance their surgical skills to an expected predetermined level. This calls for remedial measures and increase support from the faculties for providing an individualized approach and more hands-on training opportunities. OSCE based assessment and virtual online academics introduced have been well accepted by all the trainees. However, they continue to remain as adjunct to bed -side clinical training and hands on operative training.

Acknowledgement: None

Conflict of Interest: None

Source of Funding: None 


\section{REFERENCES}

1. Brindle ME, Gawande A. Managing COVID-19 in surgical systems. Ann Surg 272(1): e1-e2.

2. Zheng J., Hundeyin M., He K. General surgery chief residents' perspective on surgical education during the COVID-19 pandemic. Surgery. 2020; 168:222-225.

3. Adesoye T., Davis C.H., Del Calvo H. Optimization of surgical resident safety and education during the COVID-19 pandemiclessons learned. J Surg Educ. 2020 Jul 1.

4. G. Eyesenbach. Improving the quality of web surveys: the checklist for reporting results of internet e-surveys (CHERRIES). J. Med. Internet Res;6(2004), p e34.

5. James H.K., Pattison G.T.R. Disruption to surgical training during Covid-19 in the United States, United Kingdom, Canada, and Australasia: a rapid review of impact and mitigation efforts. J. Surg Edu 2021 January-February; 78(1): 308-314

6. L. Carenzo, E. Costantini, M. Greco, F.L. Barra, V. Rendiniello, M. Mainetti, R. Bui, A. Zanella, G. Grasselli, M. Lagioia, A. Protti, Cecconi. Hospital surge capacity in a tertiary emergency referral centre during the COVID-19 outbreak in Italy. Anaesthesia, 75 (7) (2020 Jul), pp. 928-934.

7. E Christopher Ellison, Kathryn Spanknebel, Steven C Stain et al. Impact of the COVID19 Pandemic on Surgical Training and Learner Well-Being: Report of a Survey of General Surgery and Other Surgical Specialty Educators. J Am Coll Surg; Vol. 231, No. 6, December 2020 p 613-626.

8. COVID Surg Collaborative. Elective surgery cancellations due to the COVID-19 pandemic: global predictive modelling to inform surgical recovery plans. $\mathrm{Br} \mathrm{J}$ Surg. 2020; 107:1440-1449.

9. E.M., Shaughnessy M.P., Esposito A.C. Surgical education in the time of COVID: understanding the early response of surgical training programs to the novel coronavirus pandemic. J Surg Educ. 2021 March-April; 78(2): 412-421.

10. Stambough J.B., Curtin B.M., Gililland J.M. The past, present, and future of orthopedic education: lessons learned from the COVID-19 pandemic. J Arthroplasty. 2020;35(7S):S60-S64.

11. Khalafallah A.M., Jimenez A.E., Lee R.P. Impact of COVID-19 on an academic neurosurgery department: The Johns
Hopkins experience. World Neurosurg. 2020;139: e877-e884.

12. CholeS Study Group; West Midlands Research Collaborative. Population-based cohort study of outcomes following cholecystectomy for benign gallbladder diseases. Br J Surg. 2016; 103:1704-1715.

13. Porpiglia F, Checcucci E, Amparore D, Verri P, Campi R, Claps F, Esperto F, Fiori C, Carrieri G, Ficarra V, Mario Scarpa R, Dasgupta P. Slowdown of urology residents' learning curve during the COVID-19 emergency. BJU Int. 2020 Jun;125(6):E15E17. doi: 10.1111/bju.15076.

14. Ahmed O, Walsh TN. Surgical trainee experience with open cholecystectomy and the Dunning-Kruger effect. J Surg Educ .2020; 77:1076-1081.

15. Amparore D, Claps F, Cacciamani GE et al. (2020) Impact of the COVID-19 pandemic on urology residency training in Italy. Minerva urologica e nefrologica $=$ The Italian journal of urology and nephrology 72 (4):505-509.

16. Huntley RE, Ludwig DC, Dillon JK. Early effects of COVID-19 on oral and maxillofacial surgery residency trainingresults from a National Survey. J Oral Maxillofac Surg. 2020;78(8):1257-1267.

17. Guo T, Kiong KL, Yao C, et al. Impact of the COVID-19 pandemic on Otolaryngology trainee education. Head Neck. 2020; 42:2782-2790.

18. Coe T.M., Jogerst K.M., Sell N.M. Practical techniques to adapt surgical resident education to the COVID-19 era. Ann Surg. 2020;72: e139-e141.

19. Bryan D.S., Benjamin A.J., Schneider A.B, et al. Nimble, together: a training program's response to the COVID-19 pandemic. Ann Surg. 2020; 272: e142-e143.

20. Imielski, B. The detrimental effect of COVID-19 on subspecialty medical education. Surgery 2020 Aug; 168(2): 218219.

21. C. Hope, J.J Reilly, G. Griffiths, J. Lund and D. Humes. The impact of COVID-19 on surgical training: a systematic review. Tech. Coloproctol. 2021 Jan 28: 1-16.

22. Clara Munro, Josh Burke, William Allum and Neil Mortensen. Covid-19 leaves surgical training in crisis. (editorial). BMJ 2021;372: n659

23. COVID-19 impact on Surgical Training and Recovery Planning (COVID-STAR) - A 
cross-sectional observational study. International Journal of Surgery 88 (2021) 105903.

24. Joint Committee of Surgical Training, Association of Surgeons in Training, British Orthopaedics Trainees' Association, Confederation of Postgraduate Schools of Surgery. Maximising training: making the most of every training opportunity. 2021. https://www.jcst.org/key-documents/

25. Madhuri H. Nanjundaswamy, Harish Pathak and Santosh K Chaturvedi. Perceived stress and anxiety during COVID-19 among psychiatry trainees. Asian. J. Psychiatry. 2020 Dec; 54: 102282.
26. Eman Alshdaifat, Amer Sindani, Wasim Khasawneh, OmarAbu-Azzam et al. The impact of COVID-19 pandemic on training and mental health of residents: a crosssectional study. BMC Medical Education. volume 21, Article number: 208 (2021)

How to cite this article: Kantharia CV, Pujari $\mathrm{S}$, Jain $\mathrm{K}$ et.al. Impact of COVID-19 on surgical residency training: Indian perspective - a review. Gal Int J Health Sci Res. 2021; 6(3): 62-69. DOI: https://doi.org/10.52403/ gijhsr.20210710 